\title{
Synthesis, Antimicrobial Activity and Structure-Activity Relationship of Some 5-Arylidene-thiazolidine-2,4-dione Derivatives
}

\author{
Raíssa K. C. de Paiva, ${ }^{a}$ Jamerson F. da Silva, ${ }^{a}$ Hudieyllen A. Moreira,${ }^{a}$ Osvaldo G. Pinto, ${ }^{b}$ \\ Lilian T. F. M. Camargo, ${ }^{c, d}$ Plínio L. F. Naves, ${ }^{b}$ Ademir J. Camargo, ${ }^{d}$ Luciano Ribeiro $^{d}$ \\ and Luciana M. Ramos ${ }^{\odot} *, a$
}

${ }^{a}$ Laboratório de Química Medicinal e Síntese Orgânica (LaQuiMeSO), Câmpus de Ciências Exatas e Tecnológicas, Universidade Estadual de Goiás, CP 459, 75132-400 Anápolis-GO, Brazil

${ }^{b}$ Laboratório de Microbiologia, Câmpus de Ciências Exatas e Tecnológicas, Universidade Estadual de Goiás, CP 459, 75132-400 Anápolis-GO, Brazil

'Instituto Federal de Goiás, Av. Pedro Ludovico, s/n, Residencial Reny Cury, 75131-457 Anápolis-GO, Brazil

${ }^{d}$ Grupo de Química Teórica e Estrutural de Anápolis (QTEA), Câmpus de Ciências Exatas de Anápolis, Universidade Estadual de Goiás, CP 459, 75132-400 Anápolis-GO, Brazil

\begin{abstract}
Derivatives of the thiazolidine-2,4-dione core represent a heterocyclic class with several correlated properties. In this context, the synthesis of structural analogues of these bioactive substances becomes attractive in the field of medicinal chemistry. These analogues act as antimicrobial agents against Gram-positives pathogens. The present work aimed to synthesize 10 different derivatives of 5-arylidene-thiazolidine-2,4-dione, employing urea as the catalyst in a solvent-free reaction medium, with yields that ranged from 45 to $99 \%$. The compounds obtained were submitted to an antimicrobial assay against $S$. aureus ATCC 29213. Two compounds presented minimum inhibitory concentration of 62.5 and $32.5 \mu \mathrm{g} \mathrm{mL}^{-1}$ and minimum bactericidal concentration $<500 \mu \mathrm{g} \mathrm{mL} \mathrm{mL}^{-1}$, demonstrating their antibacterial potential. Principal component analysis was carried out to discriminate the compounds in active and inactive classes. Four geometric and electronic molecular descriptors were required to completely discriminate the compounds. The selected descriptors can guide us in designing new 5-arylidene-thiazolidine-2,4-dione derivatives with enhanced activity.
\end{abstract}

Keywords: 5-arylidenethiazolidine-2,4-diones, organocatalyst, quantum chemical descriptors, principal component analysis, structure-activity relationship

\section{Introduction}

Thiazolidine-2,4-dione (TZD) is an important and privileged class of compounds that are derived from the thiazolidines. TZDs consist of a 5-member ring, and their structure contain sulfur and nitrogen atoms in positions 1 and 3, and carbonyl in position 4. Also, they can present several substituents in positions 2, 3 and 5 (Figure 1). ${ }^{1,2}$

The first reaction in order to obtain TZD was described in an aqueous medium with cyclization, employing

*e-mail: luciana.ramos@ueg.br

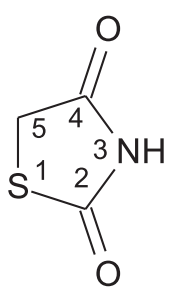

Figure 1. Nucleus of thiazolidine-2,4-dione.

monochloroacetic acid and thiourea. ${ }^{3} \mathrm{~A}$ variety of synthetic approaches have been reported involving this core, which presents several reactive sites that promote substitutions in the heterocyclic ring. These approaches have demonstrated 
the versatility of TZD under different reaction conditions to produce bioactive heterocyclic compounds. ${ }^{3-5}$

In recent years, 5-arylidene-thiazolidine-2,4-dione derivatives have been emphasized in the field of synthetic organic chemistry. ${ }^{1-3}$ Several synthetic protocols have been reported in the process of obtaining these derivatives. The 5-arylidene-thiazolidine-2,4-diones are preferentially obtained through Knoevenagel condensation of aromatic aldehydes with TZD, starting from the use of catalysts such as piperidine, nanoparticles of $\mathrm{Zn}$, oxalic acid, $\mathrm{LiBr}, \mathrm{BiCl}_{3}{ }^{3}$ $\mathrm{NaOH},{ }^{4,5}$ tetrabutylammonium bromide (TBAB), sodium acetate and piperidine benzylate. ${ }^{6,7}$ The development of new methodologies, mainly focused on Green Chemistry principles, is an important objective for a sustainable future. To this end, protocols involving aldonitrons in polyethylene glycol (PEG) through the addition-elimination process have demonstrated excellent yields in obtaining these derivatives in a shorter reaction time. ${ }^{8}$ Highly efficient, selective and chemically correct methods for the synthesis of Knoevenagel products catalyzed by ionic liquids such as 1,1,2,3-tetramethylguanidine lactate ([TMG] [Lac] $)^{9}$ and tetramethylammonium hydroxide $\left(\mathrm{Bu}_{4} \mathrm{NOH}\right)$ in aqueous medium ${ }^{10}$ have been reported in the literature. Alternative catalytic methods are also being employed. Pratap et al. ${ }^{11}$ employed an active yeast-based biocatalyst (Saccharomyces cerevisiae), which acted as a mini-reactor, producing a variety of specific enzymes essential for the synthesis of 5-arylidene-4-thiazolidinone derivatives. Synthesis of the 5-arylidene-4-thiazolidinone derivatives generally occurs under reaction conditions involving the use of toxic solvents and catalysts, excess reagents and long reaction times; such conditions result in low yields, necessitating more favorable reaction conditions via solvent-free procedures and with catalysts of low or no toxicity. ${ }^{3}$

Thiazolidine-2,4-dione derivatives are a class of heterocyclic compounds whose chemical and biological versatility is well characterized by the description of antimicrobial, ${ }^{1,2}$ antimalarial, ${ }^{12,13}$ antiviral, ${ }^{14}$ anticonvulsant ${ }^{4}$ and anti-inflammatory activities. ${ }^{15,16}$ In addition, these compounds have proved to be inhibitors of the enzyme aldose-reductase, and they are effective antioxidant agents in combating oxidative stress associated with diabetic complications and other pathologies. ${ }^{17}$

These derivatives have shown significant activity against Gram-positive bacteria such as Staphylococcus aureus, Staphylococcus epidermis, Kocuria rhizophila, Bacillus cereus, Bacillus subtilis; Gram-negative bacteria such as Escherichia coli, Pseudomonas aeruginosa and Klebsiella pneumoniae; ${ }^{18}$ and fungi such as Candida maltosa, Aspergillus niger, Aspergillus fumigatus,
Cryptococcus neoformans and Aspergillus flavus. ${ }^{18,19}$ The inhibition of microbial growth makes these compounds excellent candidates for the development of antibacterial and antifungal agents. ${ }^{19}$

Due to the biological potential of TZD derivatives, the electron spectra of these molecules have been investigated in order to explain the characteristics that determine the acidity and basicity, as well as the necessary protonation and deprotonation energies involved in the synthetic route. These energies are responsible for obtaining a series of analogs derivatives, differing from one another by the presence of substituent groups at defined positions of the chemical structure of the compounds of this class. ${ }^{7,20}$ The electronic effect of electron density withdrawers and acceptors determines their reactivity, and the effect of these groups is well described in the literature. They boost not only the kinetics of the reaction by promoting a more effective synthesis, but also increase the yield of the synthesis. ${ }^{21}$

These characteristics contribute to a better understanding of the development of new bioactive substances based on the correlation between theoretical and experimental properties, since the electronic properties of potential pharmacological agents used for the treatment of different pathologies correlate well with their respective biological activities. $^{22-24}$

In this context and bearing in mind the biological properties of the TZD class in medicinal chemistry, the present work aimed to synthesize 5-arylidene-thiazolidine2,4-dione derivatives and, subsequently, to evaluate their antimicrobial activity against Staphylococcus aureus ATCC 29213.

A quantum chemical and chemometric study ${ }^{25}$ of the 5-arylidene-2,4-thiazolidinedione analogs were also applied on the compounds to establish the relationship between molecular structure and activity against Staphylococcus aureus ATCC 29213.

\section{Experimental}

\section{General experimental procedures}

All the chemicals were obtained from Aldrich and Merck chemical company and used without further purification. Reactions were monitored by thin layer chromatography (TLC). TLC was performed on Merck 60 F-254 silica gel plates with ethyl acetate and $n$-hexane (7: 3 ) or methanol (eluent system) and visualization with ultraviolet light (UV) or development in $\mathrm{I}_{2} .{ }^{1} \mathrm{H}$ and ${ }^{13} \mathrm{C}$ nuclear magnetic resonance (NMR) spectra were acquired with Mercury Varian plus $300 \mathrm{MHz}$. Chemical shifts $(\delta)$ are reported in parts per 
million and coupling constants $(J)$ in hertz. The ${ }^{1} \mathrm{H}$ and ${ }^{13} \mathrm{C}$ chemical shifts were acquired with $\mathrm{CDCl}_{3}$ or DMSO- $d_{6}$ as deuterated solvent and tetramethysilane (TMS) as internal standard. Splitting patterns were assigned as: s for singlet, $\mathrm{br} \mathrm{s}$ for broad singlet, $\mathrm{d}$ for doublet, $\mathrm{t}$ for triplet, $\mathrm{td}$ for triplet of doublets, dd for doublet of doublets, ddd for doublet of doublet of doublets and $\mathrm{m}$ for multiplet. Melting points were determined by using a Microquímica MQAPF-301 apparatus and were uncorrected. The infrared (IR) spectra were recorded on PerkinElmer Spectrum Frontier FTIR spectrophotometer using $\mathrm{KBr}$ disc method.

\section{Synthesis of thiazolidine-2,4-dione}

In a round-bottomed flask under heating, a solution of thiourea $(10 \mathrm{~g}, 131.37 \mathrm{mmol})$ and chloroacetic acid $(12.4 \mathrm{~g}$, $131.21 \mathrm{mmol})$ in distilled water $(100 \mathrm{~mL})$ was prepared. The mixture was maintained under magnetic stirring and reflux for $18 \mathrm{~h}$ at $80^{\circ} \mathrm{C}$, and then left in the refrigerator for $24 \mathrm{~h}$. The white crystals obtained were vacuum filtered and washed with cold water.

Optimization of the reaction conditions for the synthesis of 5-arylidene-thiazolidine-2,4-dione derivatives

The previously synthesized TZD was submitted to the reaction of interest, evaluating the catalytic system, solvent influence, temperature, reaction time and excess of the selected catalyst and reactants in the reaction medium. Finally, aromatic aldehydes with different substituents at ortho, meta and para position were employed in order to obtain several 5-arylidene-thiazolidine-2,4-dione derivatives.

To a $25 \mathrm{~mL}$ flask, $50 \mathrm{mg}$ of the catalyst, $1 \mathrm{mmol}$ of TZD and $1 \mathrm{mmol}$ of aldehyde were added. The reaction mixture was maintained under constant agitation for $2 \mathrm{~h}$ at $80^{\circ} \mathrm{C}$.

After the end of the $2 \mathrm{~h}$ reaction a precipitate was obtained, which was taken out of the flask with cold ethanol, washed and filtered under vacuum pressure. Then they were recrystallized from EtOH. From the use of this methodology, several derivatives of interest were obtained.

\section{Evaluation of antimicrobial activity}

The synthesized compounds were submitted to the microdilution test in broth for the determination of minimum inhibitory concentration (MIC) and minimum bactericidal concentration (MBC). The assay was performed according to the method adopted by the Clinical and Laboratory Standards Institute (CLSI) (2010) employing a multiwell plate.
Gram-positive Staphylococcus aureus (ATCC 29213) was maintained at the Microbiology Laboratories of Universidade Estadual de Goiás (UEG). The bacterial inoculums were prepared by suspending them in sterile saline solution $(\mathrm{NaCl} 0.9 \%)$ until turbidity corresponding to 0.5 of the McFarland scale was reached, obtained by spectrophotometer reading at $625 \mathrm{~nm}$ (79 to $83 \%$ of transmittance). Next, a 1:10 dilution in saline solution was prepared to obtain a cell concentration of $10^{7} \mathrm{CFU} \mathrm{mL} \mathrm{mL}^{-1}$.

\section{Determination of minimum bactericidal concentration}

For the determination of minimum inhibitory concentration, 96-well U-bottom sterile microdilution plates were used. The compounds were solubilized in dimethylsulfoxide (DMSO) at 5\% and diluted in Mueller Hinton (MH) broth in order to obtain the concentrations of $1000,500,250,125,62.5,31.2,15.62$ and $7.81 \mu \mathrm{g} \mathrm{mL}^{-1}$. The same procedure was employed for the MIC determination of the effective antibiotic standard chloramphenicol (Inlab) in the concentrations 64, 32, 16, $8,4,2$ and $1 \mu \mathrm{g} \mathrm{mL}^{-1}$ for technique validation. Controls of bacterial viability were established: DMSO at $5 \%$, culture medium sterility and extracts. All the experiments were conducted in triplicate.

To the previously prepared concentrations in the microplate, $100 \mu \mathrm{L}$ of $\mathrm{MH}$ broth and $100 \mu \mathrm{L}$ of the compounds were added. Subsequently, $5 \mu \mathrm{L}$ of the adjusted inoculum was deposited in all wells of the microplate and the initial concentration of the inoculum

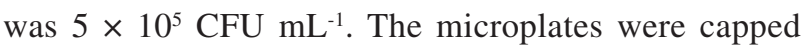
and maintained in an oven at $35{ }^{\circ} \mathrm{C}$ for $24 \mathrm{~h}$. After the incubation, the visual reading was carried out and the MIC of the compounds was determined as being the lowest concentration that inhibited visual bacterial growth.

\section{Determination of minimum bactericidal concentration}

The MBC values were determined after collecting a $100 \mu \mathrm{L}$ aliquot from the wells with absence of growth and seeded on plates containing nutrient agar, which were incubated at $35^{\circ} \mathrm{C}$ for $24 \mathrm{~h}$. The MBC was considered as the lowest concentration of the compounds that provided the total inhibition of bacterial growth.

\section{Computational procedure}

In the absence of the crystallographic structure of the thiazolidine-2,4-dione derivatives, it is important to carry out a conformational analysis on the compounds to establish the most stable conformation of the molecules. 
By checking the thiazolidine-2,4-dione derivatives we realize that just one degree of freedom is important in this analysis, namely, the $\mathrm{C}_{5}-\mathrm{C}_{3}-\mathrm{C}_{7}-\mathrm{H}_{19}$ dihedral angle. The conformational search performed on this dihedral angle was carried out using the molecular mechanics method with the force field MM+. ${ }^{26} \mathrm{Next}$, the conformation with the lowest energy (the most stable) of the most active compound was picked out. For the remaining derivatives, it was picked out the conformation found that most resemble the conformation selected of the most active compound. This computational procedure ensures that all derivatives will be compared at the same level of importance with respect to the molecular geometry. The selected conformations were optimized at M062X/6-311+G(d,p $)^{27}$ level of theory as implemented in g09 package of program. ${ }^{28}$ The local minimum on the hypersurface of the potential energy was confirmed by the absence of the imaginary frequencies for each molecule. All the geometric and electronic molecular descriptors were obtained at the same level of theory used for optimization.

The correlation between the molecular descriptors and the biological activity against the Staphylococcus aureus ATCC 29213 was done using the principal component analysis (PCA) as implemented in the R-Project. ${ }^{29} \mathrm{PCA}$ is a multivariate statistical method that allows us to reduce the data dimensionality from a large data set without loss of information. The reduction of the data is possible because the variables are highly correlated. For this purpose, we construct new variables (PC's) that are linear combinations of the original variables (descriptors) in such a way that the PC's are totally uncorrelated, i.e., they are orthogonal each other. In generally, the PC's are ordered in such a way that the $\mathrm{PC} 1$ account for the maximum of the data variance, the PC2 retain the second amount of the total variance of the data set, and so on.

\section{Results and Discussion}

Synthesis of thiazolidine-2,4-dione and optimization of the reaction conditions of its derivatives

In a first set of experiments, different catalysts were tested in the reaction medium, such as $\mathrm{FeCl}_{3}$, triethyl benzyl ammonium chloride (TEBAC), sodium acetate and urea, and then the effect of the following solvents was analyzed: $\mathrm{EtOH}, \mathrm{H}_{2} \mathrm{O}, \mathrm{MeCN}$. It was verified that use of urea as catalyst allowed a yield of $80 \%$ of the product of interest. In contrast, the other catalysts evaluated did not allow the product to be obtained. Hence, urea was fixed as the reaction catalyst for the subsequent evaluations of reaction conditions. With the usage of different solvents in the reaction medium, the product could not be obtained, so a solvent-free medium was chosen.

After the establishment of a general protocol for the synthesis of 5-arylidene-thiazolidine-2,4-dione derivatives, different aromatic aldehydes with substituents at ortho, meta and para positions were employed as shown at Table 1.

The 5-arylidene-thiazolidine-2,4-dione derivatives were obtained via Knoevenagel condensation. The yield of the derivatives ranged from 45 to $99 \%$, so it can be inferred that the steric and electronic effect of the substituted aldehydes at ortho, meta and para positions did not influence the yields of the product. This was to be expected, since it is reported in the literature that TZD can undergo condensation reactions of the aldol type involving the methylene group at the 5-position of the ring, due to the nucleophilic character of the methylene carbon. It becomes more evident that the reduction of the nucleophilic character and the formation of a carbanion in the presence of a base depends on the electron withdrawing effect of the adjacent carbonyl, as well as on the presence of other electron withdrawing groups at the 2-position of the ring. ${ }^{3}$

\section{Evaluation of antimicrobial activity}

The tests showed that some synthesized 5-arylidenethiazolidine-2,4-dione derivatives presented antibacterial activity, especially compounds $3 \mathbf{f}$ (with MIC of $62.5 \mu \mathrm{g} \mathrm{mL}^{-1}$ ) and $\mathbf{3 j}$ (with MIC of $31.25 \mu \mathrm{g} \mathrm{mL} \mathrm{mL}^{-1}$ ). Both compounds presented $\mathrm{MBC}>500 \mu \mathrm{g} \mathrm{mL}^{-1}$. The antimicrobial activity of this series of compounds appears to be optimized with the combination of functional groups. The MIC and MBC values obtained in this study demonstrate the antimicrobial action of compounds $\mathbf{3 f}$ and $\mathbf{3} \mathbf{j}$ on the cell growth of S. aureus ATCC 29213.

The MBC of all the compounds were higher than the maximum concentration tested $\left(500 \mu \mathrm{g} \mathrm{mL}^{-1}\right)$, even for compounds $\mathbf{3 f}$ and $\mathbf{3 j}$, which were active against the test bacteria, and showed MIC of 62.5 and $31.25 \mu \mathrm{g} \mathrm{mL} L^{-1}$, respectively. This result demonstrates that the 5 -arylidenethiazolidine-2,4-dione derivatives that are active against S. aureus presented predominantly bacteriostatic action, since it only inhibited bacterial growth. Compounds 3a-e and 3g-i had a lower antimicrobial activity, while compounds $\mathbf{3 a}, \mathbf{3 d}$ and $\mathbf{3 g}$ presented MBC of $125 \mu \mathrm{g} \mathrm{mL}^{-1}$; in general, they showed a slight antimicrobial activity. Compounds $\mathbf{3 c}$ and $\mathbf{3 h}$ had MIC $>500 \mu \mathrm{gL}^{-1}$ against S. aureus ATCC 29213. All compounds presented $\mathrm{MBC}>500 \mu \mathrm{g} \mathrm{mL}^{-1}$ (Table 2). 
Table 1. 5-Arylidene-thiazolidine-2,4-dione derivatives synthesized<smiles>CC1CCCCCC[R]1c1ccc(/C=C2/C(=O)NC(=O)C2=O)cc1</smiles>

\begin{tabular}{|c|c|c|c|c|}
\hline entry & Aldehyde & Compound & Product & Yield $/ \%$ \\
\hline 1 & & $3 a$ & & 80 \\
\hline 2 & & $3 b$ & & 50 \\
\hline 3 & & $3 c$ & & 99 \\
\hline 4 & & 3d & & 89 \\
\hline 5 & & $3 e$ & & 62 \\
\hline 6 & & $3 f$ & & 72 \\
\hline 7 & & $3 g$ & & 75 \\
\hline 8 & & $3 h$ & & 81 \\
\hline 9 & & $3 \mathbf{i}$ & & 73 \\
\hline 10 & & $3 \mathbf{j}$ & & 45 \\
\hline
\end{tabular}

aConditions: $0.833 \mathrm{mmol}$ of ureia, $1 \mathrm{mmol}$ of TZD and $1 \mathrm{mmol}$ of aldehyde; $2 \mathrm{~h}$ of reaction at $100{ }^{\circ} \mathrm{C}$. 
Table 2. Determination of minimum inhibitory concentration and minimum bactericidal concentration of 5-arylidene-thiazolidine-2,4-dione derivatives against Staphylococcus aureus ATCC 29213

\begin{tabular}{lcc}
\hline Compound & $\mathrm{MIC} /\left(\mu \mathrm{g} \mathrm{mL}^{-1}\right)$ & $\left.\mathrm{MBC} /(\mu \mathrm{g} \mathrm{mL})^{-1}\right)$ \\
\hline 3a & 125 & $>500$ \\
3b & 500 & $>500$ \\
3c & $>500$ & $>500$ \\
3d & 125 & $>500$ \\
3e & 125 & $>500$ \\
3f & 62.5 & $>500$ \\
3g & 125 & $>500$ \\
3h & $>500$ & $>500$ \\
3i & 250 & $>500$ \\
3j & 31.25 & $>500$ \\
\hline
\end{tabular}

MIC: minimum inhibitory concentration; $\mathrm{MBC}$ : minimum bactericidal concentration; chloramphenicol with MIC between 2-16 $\mu \mathrm{g} \mathrm{mL}^{-1}$ was used as the standard for antibacterial activities.

In accordance with Holetz et al., ${ }^{21}$ compounds with MIC below $100 \mu \mathrm{g} \mathrm{mL}^{-1}$ present significant antimicrobial activity; following this criterion, compounds $\mathbf{3 f}$ and $\mathbf{3 j}$ were active against Staphylococcus aureus ATCC 29213.

Several studies with 5-arylidene-thiazolidine-2,4-dione derivatives demonstrated the antimicrobial potential of these compounds. Gouveia et al..$^{22}$ evaluated the antibacterial activity of compound $\mathbf{3} \mathbf{f}$ and reported activity against several Gram-positive bacteria, including Staphylococcus aureus, with MIC from 4-8 $\mu \mathrm{g} \mathrm{mL}^{-1}$.

The mechanism of antimicrobial activity of 5-arylidene-thiazolidine-2,4-dione derivatives in general is due to the presence of these substituents $\left(\mathrm{NO}_{2}, \mathrm{Cl}, \mathrm{F}\right.$ and $\mathrm{Br}$ ), these groups considerably increase the lipophilic character of these molecules, such character facilitates the crossing of the molecule through the microbial cytoplasmic membrane inhibiting its growth. Zidar et al. ${ }^{30}$ reported in their studies that pharmacophore substituents present on 5-arylidene-thiazolidine-2,4-dione derivatives considerably increase the antimicrobial activity of these compounds, yet according to these authors such molecules probably act on the synthesis of wall peptidoglycan cell growth of Gram-positive bacterial, which in turn justifies the antibacterial inhibition of Gram-positive bacterial by these molecules.

Zvarec et al..$^{23}$ observed that compound 3a presented cell-mediated immunity $(\mathrm{CMI})<64 \mu \mathrm{g} \mathrm{mL}^{-1}$ against S. aureus ATCC 31890 and CMI of $125 \mu \mathrm{g} \mathrm{mL}^{-1}$ against S. aureus ATCC 29213. According to the authors, this may be related to the weak lipophilic characteristics that some of the compounds may present hindering the diffusion by the membranes of the bacterial.
Another interesting finding was the MIC of $125 \mu \mathrm{g} \mathrm{mL}^{-1}$ of compound 3e. According to the authors, compounds with hydroxy substituents are less active than those that are meta-substituted, and this occurs as a result of the intramolecular between the carboxyl group and the ortho-hydroxy substituent.

There are few reports involving the antimicrobial activity of 5-arylidene-thiazolidine-2,4-dione derivatives. Generally, these derivatives are subjected to ring substitution at the 3-position and carbonyl substitution by thiocarbonyl, and the results have demonstrated efficient antimicrobial activity. ${ }^{23}$

\section{Structure-activity relationship against Staphylococcus aureus ATCC 29213}

Table 3 shows the atomic numbering used throughout the calculations of the molecular descriptors. There is, at first, no reason to consider one descriptor more important than the other in the search for the correlation between molecular descriptors and the activity against Staphylococcus aureus ATCC 29213. Therefore, one must give the same weight to the descriptors in the principal component analysis. That is done by autoscaling the descriptors, i.e., all descriptors were mean centered and divided by standard deviation according to the equation $\mathrm{x}_{\mathrm{ij}}=\left(\mathrm{x}_{\mathrm{i}}-\overline{\mathrm{x}}_{\mathrm{i}}\right) / \mathrm{s}_{\mathrm{i}}$, where $\mathrm{x}_{\mathrm{ij}}$ stands for descriptor for the molecule $\mathrm{j}$; $\overline{\mathrm{x}}_{\mathrm{i}}$ is the mean value for the descriptor $i$, and $s_{i}$ stands for the respective standard deviation. With this procedure, one can compare all descriptors at the same level of importance, although they have different units.

Another chemometric technique used to guide us in selecting the best variables to be used in the PCA analysis was the Fisher's weight. ${ }^{31}$ Molecular descriptors with higher Fisher's weight values are good candidates to be used in the PCA analysis. This technique can save us a lot of time in searching for good variables to be used in PCA analysis to classify the compounds in active and inactive classes. This procedure has been applied with success in similar works. ${ }^{32-37}$

By applying PCA procedure on the selected descriptors by Fisher's weight, after many attempts, the best result was obtained with four molecular descriptors: dipole moment $(\mu)$, bond angle between atoms 5, 6 and $18\left(\mathrm{~A}_{5-6-18}\right)$, partial atomic charge on atom $18\left(\mathrm{Q}_{18}\right)$ and bond orders between atoms 5 and $17\left(\mathrm{O}_{5-17}\right)$.

As shown in Figure 2, the PC1 is responsible alone for the classification of the compounds in active and inactive classes. The PC1 component responds alone for about $53.39 \%$ of the total of variance of the data set. PC1 and PC2 account together for $83.20 \%$ of the total variance of 
Table 3. Atomic numbering for 5-arylidene-thiazolidine-2,4-dione derivatives used throughout the calculation

\begin{tabular}{|c|c|c|c|}
\hline \multirow{2}{*}{ Compound } & \multicolumn{3}{|c|}{ Atom numbering for the substituents } \\
\hline & 15 & 16 & 21 \\
\hline 3a & $\mathrm{H}$ & $\mathrm{H}$ & $\mathrm{H}$ \\
\hline $3 \mathbf{b}$ & $\mathrm{H}$ & $\mathrm{H}$ & $\mathrm{NO}_{2}$ \\
\hline $3 c$ & $\mathrm{H}$ & $\mathrm{O}$ & $\mathrm{O}$ \\
\hline 3d & $\mathrm{H}$ & $\mathrm{H}$ & $\mathrm{OH}$ \\
\hline $3 e$ & $\mathrm{OH}$ & $\mathrm{H}$ & $\mathrm{H}$ \\
\hline $3 f$ & $\mathrm{H}$ & $\mathrm{Cl}$ & $\mathrm{H}$ \\
\hline $3 g$ & $\mathrm{H}$ & $\mathrm{OCH}_{3}$ & $\mathrm{H}$ \\
\hline $3 \mathrm{~h}$ & $\mathrm{H}$ & $\mathrm{NCH}_{3} \mathrm{CH}_{3}$ & $\mathrm{H}$ \\
\hline $3 \mathbf{i}$ & $\mathrm{H}$ & $\mathrm{OH}$ & $\mathrm{OCH}_{3}$ \\
\hline $3 \mathbf{j}$ & $\mathrm{H}$ & $\mathrm{NO}_{2}$ & $\mathrm{H}$ \\
\hline
\end{tabular}

the original data. So, the PC1 and PC2 represent very well the dimensionality of the variance of the descriptors space.

From Table 4, we can see that all selected descriptors have positive values, and Figure 2a shows that the active compounds have negative scores. According to Figure $2 b$ and equation 1 for $\mathrm{PC} 1$, which is responsible for the classification, for a compound to be classified in the active class, it should have lower values for the descriptors dipole moment, $\mathrm{Q}_{18}$ and bond order $\mathrm{O}_{5-17}$, and higher value for $\mathrm{A}_{5-6-18}$. On the other hand, a compound will be classified in the inactive class if it has higher $\mu, \mathrm{Q}_{18}$ and $\mathrm{O}_{5-17}$ and lower $\mathrm{A}_{5-6-18}$ value.

$$
\mathrm{PC} 1=+0.581 \mu-0.491 \mathrm{~A}_{5-6-18}+0.316 \mathrm{Q}_{18}+0.565 \mathrm{O}_{5-17}
$$

It is important to note that the descriptors $\mathrm{A}_{5-6-18}, \mathrm{Q}_{18}$, and $\mathrm{O}_{5-17}$ are close related to the benzene ring, while the descriptors related to the methylenethiazolidine-2,4-dione group did not prove to be important to discriminate the compounds. The only selected descriptor that is not exclusively related to benzene ring is the total dipole moment $(\mu) . \mu$ is an important electronic descriptor that depends on the entire molecule and it is a measure of the charge separation on the molecular system. In addition, it is closely related to the solubility of the compound in the medium.

From the selected descriptors by PC1, one can assume that the activity is related to benzene ring and its substituent groups. The substituent groups that decrease the dipole moment, the partial charge on atom 18 , bond order between atoms 5 and 17, the increase in the bond angle between atoms 5, 6 and 18, are responsible for making the compound to be active against Staphylococcus aureus ATCC 29213. In addition, as the activity is correlated with the decrease of the bond order $\mathrm{O}_{5-17}$ and since the atom 17 is a hydrogen atom for all compounds, it can be assumed that the $\mathrm{H}_{17}$ is interacting with the target site of the Staphylococcus aureus ATCC 29213.

Therefore, in designing new compounds that can exhibit activity against Staphylococcus aureus ATCC 29213 we should take in consideration the four selected descriptors, i.e., one must select substituent groups in the benzene ring that can modify the descriptors according to equation 1.

\section{Conclusions}

With the results obtained, it is concluded that the methodology employed for the synthesis of arylidene derivatives was an efficient alternative in obtaining them, and it is chemically clean, since the catalyst employed is non-toxic. It was possible to synthesize 10 different

Table 4. Electronic and geometric parameter selected for principal component analysis

\begin{tabular}{lccccc}
\hline Compound & & Dipole moment $(\mu) /$ debye & Bond angle $\mathrm{A}_{5-6-18} /$ degree & Atomic charge $\mathrm{Q}_{18} /$ (a.u.) & Bond order $\mathrm{O}_{5-17} /$ (a.u.) \\
\hline $\mathbf{3 a}$ & inactive & 3.1973 & 119.90 & 0.097255 & 0.9229 \\
$\mathbf{3 b}$ & inactive & 4.9826 & 120.03 & 0.111586 & 0.9205 \\
$\mathbf{3 c}$ & inactive & 3.8561 & 121.95 & 0.166930 & 0.9225 \\
$\mathbf{3 d}$ & inactive & 4.4923 & 120.00 & 0.107659 & 0.9219 \\
$\mathbf{3 e}$ & inactive & 4.5873 & 120.22 & 0.106788 & 0.9224 \\
$\mathbf{3 f}$ & active & 1.6363 & 120.98 & 0.110633 & 0.9208 \\
$\mathbf{3 g}$ & inactive & 4.1326 & 121.55 & 0.139805 & 0.9226 \\
$\mathbf{3 h}$ & inactive & 7.0838 & 118.80 & 0.149931 & 0.9236 \\
$\mathbf{3 i}$ & inactive & 3.3606 & 120.13 & 0.139051 & 0.9223 \\
$\mathbf{3 j}$ & active & 3.1789 & 121.82 & 0.109172 & 0.9189 \\
\hline
\end{tabular}



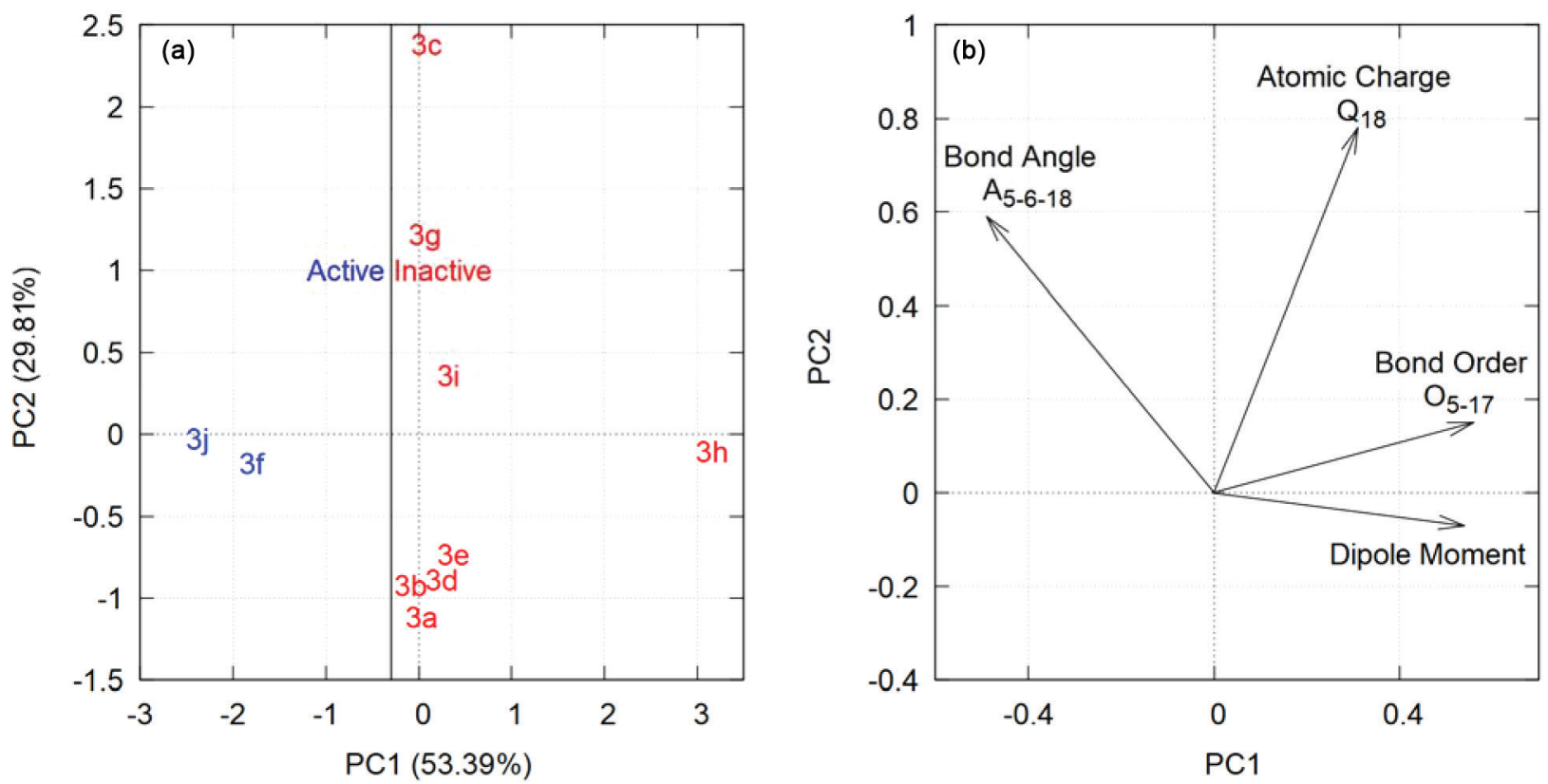

Figure 2. (a) Scores plot for the ten compounds. The active compounds are at left side of the picture (blue color). The inactive compounds are on the right (red color); (b) loading plot of the molecular descriptors selected by PCA model.

5-arylidene-thiazolidine-2,4-dione derivatives with the proposed methodology, with yields that ranged from 45 to $99 \%$. The results of antimicrobial screening revealed the potential of the compounds obtained as new antibacterial agent candidates, thus also evidencing the biological potential of TZD derivatives. Compounds $\mathbf{3 f}$ and $\mathbf{3 j}$ showed the most significant results against $S$. aureus ATCC 29213. Four descriptors were selected from the PCA analysis that explain very well the structure-activity relationship against $S$. aureus ATCC 29213. PC1 is alone responsible for the classification and it accounts for about $53 \%$ of the total variance of the selected descriptors. The selected molecular descriptors were bond angle between 5, 6 and 18 atoms, atomic partial charge on atom 18, dipole moment and bond orders between 5 and 17 atoms. From these results, we can conclude that the electronic aspect of the analogue derivatives play important role in the activity and they strongly suggest that the hydrogen at position 17 is involved in the activity. In addition, the selected descriptors also can guide us in designing new 5-arylidene-thiazolidine-2,4-dione analogs with enhanced activity against $S$. aureus ATCC 29213. The synthesized derivatives are reported in the literature, but there are not studies on the structure-activity relationships of these derivatives from chemometric techniques. The structures of thiazolidine-2,4-diones differ in the substitution pattern. Therefore, they may be considered analogous allowing using of structure-activity relationships based computational models and can likely to exhibit similar biological activities.

\section{Supplementary Information}

Supplementary information is available free of charge at http://jbcs.sbq.org.br as PDF file

\section{Acknowledgments}

The authors are grateful for the financial support from the Universidade Estadual de Goiás pró-projetos pesquisa 029/2016, Conselho Nacional de Desenvolvimento Científico e Tecnológico (CNPq), Universal 01/2016 and Fundação de Amparo à Pesquisa do Estado de Goiás (FAPEG). The research was developed with support of the High Performance Computing Center at the UEG. Plínio L. F. Naves, Luciano Ribeiro and Luciana M. Ramos, in particular, express their gratitude to PROBIP-UEG.

\section{References}

1. Naim, M. J.; Alam, M. J.; Ahmad, S.; Nawaz, F.; Shrivastava, N.; Sahu, M.; Alam, O.; Eur. J. Med. Chem. 2017, 129, 218.

2. Alegaon, S. G.; Alagawadi, K. R.; Med. Chem. Res. 2012, 21 , 816.

3. Shah, S.; Singh, B.; Bioorg. Med. Chem. Lett. 2012, 22, 5388.

4. Barros, C. D.; Amato, A. A.; de Oliveira, T. B.; Iannini, K. B. R.; da Silva, A. L.; da Silva, T. G.; Leite, E. S.; Hernandes, M. Z.; de Lima, M. C. A.; Galdino, S. L.; Bioorg. Med. Chem. 2010, 18,3805 .

5. Ottanà, R.; Maccari, R.; Giglio, M.; del Corso, A.; Cappiello, M.; Mura, U.; Cosconati, S.; Marinelli, L.; Novellino, E.; 
Sartini, S.; la Motta, C.; da Settimo, F.; Eur. J. Med. Chem. 2011, 46, 2797.

6. Lohray, B. B.; Bhushan, V.; Rao, P. B.; Madhavan, G. R.; Murali, N.; Rao, K. N.; Madhavan, G. R.; Murali, N.; Rao, K. N.; Reddy, A. K.; Rajesh, B. M.; Reddy, P. G.; Chakrabarti, R.; Rajagopalan, R.; Bioorg. Med. Chem. Lett. 1997, 7, 785.

7. Goés, A. S.; Lima, W. T.; Nagy, H. J.; Alves, A. J.; Faria, A. R.; Lima, J. G.; Maia, M. B. S.; Quim. Nova 2004, 27, 905.

8. Kumar, D.; Narwal, S.; Sandhu, J. S.; Int. J. Med. Chem. 2013, 2013, 1.

9. Suresh; Sandhu, J. S.; Org. Med. Chem. Lett. 2013, 3, 2.

10. Khazaei, A.; Veisi, H.; Safaei, M.; Ahmadian, H.; J. Sulfur Chem. 2014, 35, 270.

11. Pratap, U. R.; Jawale, D. V.; Waghmare, R. A.; Lingampalle, D. L.; Mane, R. A.; New J. Chem. 2011, 35, 49.

12. Anthony, M. P.; Burrows, J. N.; Duparc, S.; Moehrle, J. J.; Wells, T. N.; Malar. J. 2012, 11, 316.

13. Sharma, R. K.; Younis, Y.; Mugumbate, G.; Njoroge, M.; Gut, J.; Rosenthal, P. J.; Chibale, K.; Eur. J. Med. Chem. 2015, 90, 507.

14. Verma, A.; Saraf, S. K.; Eur. J. Med. Chem. 2008, 43, 897.

15. Santos, L. C.; Uchōa, F. T.; Canas, A. R. P. A.; Sousa, I. A.; Moura, R. O.; Lima, M. C. A.; Galdino, S. L.; Pitta, I. R.; Barbe, J.; Heterocycl. Commun. 2005, 11, 121.

16. Maccari, R.; del Corso, A.; Giglio, M.; Moschini, R.; Mura, U.; Ottanà, R.; Bioorg. Med. Chem. Lett. 2011, 21, 200.

17. Khazaei, A.; Veisi, H.; Safaei, M.; Ahmadian, H.; J. Sulfur Chem. 2014, 35, 270.

18. Bharti, S. K.; Nath, G.; Tilak, R.; Singh, S. K.; Eur. J. Med. Chem. 2010, 45, 651.

19. Abdel-Wahab, B. F.; Abdel-Aziz, H. A.; Ahmed, E. M.; Eur. J. Med. Chem. 2009, 44, 2632.

20. Taniyama, H.; Yusa, T.; Tabuchi, T.; Uchida, H.; Yakugaku Zasshi 1956, 76, 154.

21. Holetz, F. B.; Pessini, G. L.; Sanches, N. R.; Cortez, D. A. G.; Nakamura, C. V.; Dias Filho, B. P.; Mem. Inst. Oswaldo Cruz 2002, 97, 1027.

22. Gouveia, F. L.; de Oliveira, R. M. B.; de Oliveira, T. B.; da Silva, I. M.; do Nascimento, S. C.; de Sena, K. X. F. R.; de Albuquerque, J. F. C.; Eur. J. Med. Chem. 2009, 44, 2038.
23. Zvarec, O.; Polyak, S. W.; Tieu, W.; Kuan, K.; Dai, H.; Pedersen, D. S.; Morona, R.; Zhang, L.; Booker, G. W.; Abell, A. D.; Bioorg. Med. Chem. Lett. 2012, 22, 2720.

24. Liu, X. F.; Zheng, C. J.; Sun, L. P.; Liu, X.-K.; Piao, H. R.; Eur. J. Med. Chem. 2011, 46, 3469.

25. Kokot, S.; Grigg, M.; Panayiotou, H.; Phuong, T. D.; Electroanalysis 1998, 10, 1081.

26. Allinger, N. L.; Allinger, J. A.; Yan, L. Q.; J. Mol. Struct.: THEOCHEM 1989, 201, 363.

27. Walker, M.; Harvey, A. J. A.; Sen, A.; Dessent, C. E. H.; J. Phys. Chem. A 2013, 117, 12590.

28. Schmid, M.; Steinlein, C.; Bogart, J. P.; Feichtinger, W.; Haaf, T.; Nanda, I.; del Pino, E. M.; Duellman, W. E.; Hedges, S. B.; Cytogenet. Genome Res. 2012, 138, 341.

29. R Development Core Team; RStudio, R: A Language and Environment for Statistical Computing; The R Foundation for Statistical Computing, Vienna, Austria, 2017.

30. Zidar, N.; Tomašić, T.; Šink, R.; Kovač, A.; Patin, D.; Blanot, D.; Contreras-Martel, C.; Dessen, A.; Premru, M. M.; Zega, A.; Gobec, S.; Mašič, L. P.; Kikelj, D.; Eur. J. Med. Chem. 2011, $46,5512$.

31. Mosteller, F.; Fisher, R. A.; Am. Stat. 1948, 2, 30.

32. Silva, W. A.; Andrade, C. K. Z.; Napolitano, H. B.; Vencato, I.; Lariucci, C.; de Castro, M. R. C.; Camargo, A. J.; J. Braz. Chem. Soc. 2013, 24, 133.

33. Martins, G. R.; Napolitano, H. B.; Camargo, L. T. F. M.; Camargo, A. J.; J. Braz. Chem. Soc. 2012, 23, 2183.

34. Camargo, A. J.; Honório, K. M.; Mercadante, R.; Molfetta, F. A.; Alves, C. N.; da Silva, A. B. F.; J. Braz. Chem. Soc. 2003, $14,809$.

35. Camargo, L. T. F. M.; Sena, M. M.; Camargo, A. J.; SAR QSAR Environ. Res. 2009, 20, 537.

36. Souza, J.; Santos, R. H. A.; Ferreira, M. M. C.; Molfetta, F. A.; Camargo, A. J.; Honório, K. M.; da Silva, A. B. F.; Eur. J. Med. Chem. 2003, 38, 929.

37. dos Santos, D. L.; Paula, C. B.; Carvalho-Silva, V. H.; Camargo, A. J.; Camargo, L. T. F. M.; Rev. Virtual Quim. 2016, 8, 506.

Submitted: May 11, 2018

Published online: August 28, 2018 